\title{
Effects of submaximal exercise with water ingestion on intraocular pressure in healthy human males
}

\author{
M.A. Moura ${ }^{1}$, \\ L.O.C. Rodrigues², \\ Y. W aisberg', \\ H.G. de Almeida ${ }^{1}$ \\ and E. Silami-Garcia²
}

\author{
${ }^{1}$ Faculdade de Medicina and ${ }^{2}$ Laboratório de Fisiologia do Exercício, \\ Universidade Federal de M inas Gerais, Belo Horizonte, MG, Brasil
}

\section{Correspondence \\ L.O.C. Rodrigues \\ Av. Presidente Carlos Luz, 4664 \\ 31310-250 Belo Horizonte, M G Brasil \\ Fax: + 55-31-3499-2325 \\ E-mail: lor@ eef.ufmg.br}

Research supported by CNPq and CAPES.

Received July 25, 2001

Accepted October 2, 2001

\section{Abstract}

The effects of exercise and water replacement on intraocular pressure (IOP) have not been well established. Furthermore, it is not known whether the temperature of the fluid ingested influences the IOP response. In the present study we determined the effect of water ingestion at three temperatures $\left(10,24\right.$ and $38^{\circ} \mathrm{C} ; 600 \mathrm{ml} 15 \mathrm{~min}$ before and $240 \mathrm{ml} \mathrm{15,30}$ and $45 \mathrm{~min}$ after the beginning of each experimental session) on the IOP of six healthy male volunteers (age $=24.0 \pm 3.5$ years, weight $=67.0 \pm 4.8 \mathrm{~kg}$, peak oxygen uptake $\left(\mathrm{VO}_{2 \text { peak }}\right)=47.8 \pm$ $\left.9.1 \mathrm{ml} \mathrm{kg}^{-1} \mathrm{~min}^{-1}\right)$. The subjects exercised until exhaustion on a cycle ergometer at a $60 \% \mathrm{VO}_{2 \text { peak }}$ in a thermoneutral environment. IOP was measured before and after exercise and during recovery $(15,30$ and 45 min) using the applanation tonometry method. Skin and rectal temperatures, heart rate and oxygen uptake were measured continuously. IOP was similar for the right eye and the left eye and increased postwater ingestion under both exercising and resting conditions $(\mathrm{P}<0.05)$ but did not differ between resting and exercising situations, or between the three water temperatures. Time to exhaustion was not affected by the different water temperatures. Rectal temperature, hydration status, heart rate, oxygen uptake, carbon dioxide extraction and lactate concentration were increased by exercise but were not affected by water temperature. We conclude that IOP was not affected by exercise and that water ingestion increased IOP as expected, regardless of water temperature.

Physical effort is an integral part of all sports, recreational and professional activities and programs for the prevention and treatment of diseases. Exercise is recommended for patients with cardiac disease, osteoporosis and several other health problems (1). Many of these patients are older and more prone to suffer from ocular hyper-

\section{Key words} - Exercise

- Intraocular pressure

- Thermal regulation

- Water ingestion tension or glaucoma. Water replacement during exercise is recommended in many situations (1). The effects of exercise, coupled with the ingestion of water upon intraocular pressure (IOP), are yet to be clearly established.

The effects of physical exercise on IOP have received some attention since the be- 
ginning of the 20th century (2) and there have been reports suggesting that IOP decreases during exercise (2-9). However, these studies often failed to control for variables such as the type, intensity and duration of exercise, or subject age and level of fitness and possible tonometric errors (10). Thus, definite conclusions concerning IOP changes due to exercise cannot be reached.

The metabolic muscular heat produced during exercise increases body temperature and activates thermoregulatory mechanisms to dissipate excess heat. In hot environments, sweat is the main mechanism for heat loss during exercise, leading to weight loss. Sweat contains small amounts of minerals such as sodium and potassium (1). Profuse sweating may lead to changes in plasma osmolarity, which could affect IOP.

Under certain conditions, hyperthermia induced by physical exercise may be hazardous to health and physical performance. To counteract the effects of dehydration, sweat losses during exercise must be replaced with adequate amounts of water (1).

In experimental studies on rabbits, severe hypothermia caused a decrease in IOP, while hyperthermia caused an increase in IOP (10) and a decrease in IOP was reported after exposing the cornea to cold air.

The literature shows that water ingestion affects IOP in humans. It was observed that $78 \%$ of healthy volunteers showed an increase of $2.7 \mathrm{mmHg}$ in IOP $10 \mathrm{~min}$ after drinking $1000 \mathrm{ml}$ of water and progressive increases in IOP during a period of $30 \mathrm{~min}$, and a return to basal levels within the next 30 $\min (11)$.

The purpose of the present study was to investigate the IOP responses of a group of healthy male volunteers who ingested water at three different temperatures during prolonged submaximal exercise.

Six healthy male volunteers participated in this study (age: $24.0 \pm 3.5$ years; weight: $67.0 \pm 4.8 \mathrm{~kg}$; peak oxygen uptake $\left(\mathrm{VO}_{2 \text { peak }}\right)$ : $47.8 \pm 9.1 \mathrm{ml} \mathrm{kg}^{-1} \mathrm{~min}^{-1}$, and body fat: $9.5 \pm$
$2.0 \%$ ). A routine ophthalmologic examination consisting of refraction, biomicroscopy, indirect binocular ophthalmoscopy, keratometry and applanation tonometry was performed prior to participation in the experiment.

The criteria for participant inclusion in the study were: 1) informed written consent to participate in the study; 2) having a normal eye and clinical examination; 3 ) aged 20 to 30 years; 4) a non-smoker; 5) having $\mathrm{VO}_{2 \text { peak }}$ equal to or greater than $35 \mathrm{ml} \mathrm{kg}^{-1}$ $\min ^{-1}$.

The research conformed to the International Ethical Guidelines for Biomedical Research Involving Human Subjects (WHO) and was approved by the Human Subjects Committee of the School of Physical Education of the Federal University of Minas Gerais. The participants were instructed to maintain a standard diet and to be alcohol and caffeine free while they participated in the study. They were also asked to refrain from any intense physical exercise during the $48 \mathrm{~h}$ preceding each experiment. All experimental procedures were performed in the exercise physiology laboratory.

All volunteers completed a questionnaire about their daily life for the three days preceding the experiment. After they reported to the laboratory, they rested for $20 \mathrm{~min}$ before measurement of basal IOP, heart rate and rectal and skin temperatures. After the basal measurements, the participants began each experimental session.

The subjects were submitted to six experimental conditions: exercising with an intake of $1320 \mathrm{ml}$ of water at $38^{\circ} \mathrm{C}$, resting for $45 \mathrm{~min}$ with an intake of $1320 \mathrm{ml}$ of water at $38^{\circ} \mathrm{C}$, exercising with an intake of $1320 \mathrm{ml}$ of water at $24^{\circ} \mathrm{C}$, resting with an intake of $1320 \mathrm{ml}$ of water at $24^{\circ} \mathrm{C}$, exercising with an intake of $1320 \mathrm{ml}$ of water at $10^{\circ} \mathrm{C}$, and resting with an intake of $1320 \mathrm{ml}$ of water at $10^{\circ} \mathrm{C}$.

The exercise consisted of pedaling on a Monark cycle ergometer at $60 \%$ of $\mathrm{VO}_{2 \text { peak }}$. 
The exercise was discontinued when the volunteers could no longer maintain the initial power output. During the resting condition, the subjects remained seated for 45 min.

Water ingestion was $600 \mathrm{ml} 15 \mathrm{~min}$ before each experimental session and $240 \mathrm{ml}$ 15,30 and $45 \mathrm{~min}$ after the beginning of each experimental session (exercise or rest).

The water temperatures were selected to produce physical cooling $\left(10^{\circ} \mathrm{C}\right)$, to simulate body temperature $\left(38^{\circ} \mathrm{C}\right)$ and to reach an intermediate point $\left(24^{\circ} \mathrm{C}\right)$.

IOP was measured by the applanation tonometry method using a Haag-Streit Goldmann tonometer, model R 900 , prior to the intake of $600 \mathrm{ml}$ of water, $10 \mathrm{~min}$ after the intake of $600 \mathrm{ml}$ of water, just after the end of each experimental session (exercising or resting), and 15, 30 and $45 \mathrm{~min}$ after the end of each session.

There was a 3-day interval between the different experimental conditions and each volunteer performed the sequence of experiments at the same time of day.

Skin and rectal temperatures were monitored continuously with Yellow Springs thermistors, a probe and a telethermometer. Heart rate was monitored continuously and recorded at 3-min intervals using a Polar Vantage ${ }^{\circledR}$ XLTM monitor. Oxygen uptake was measured using a gas analyzer (ErichJaeger, Cologne, Germany). The temperature and air relative humidity during the experiments ranged from 22.4 to $22.8^{\circ} \mathrm{C}$ and 62.6 to $65 \%$, respectively.

The experimental design followed a Latin square model in which six volunteers were submitted to six experimental conditions. In each experimental condition, six measurements of IOP were made to provide 216 samples. Data were analyzed by ANOVA and by the Tukey test for post hoc comparisons. The significance level adopted was $\mathrm{P}<0.05$.

The results were similar when the right eye and the left eye were compared. A statis-

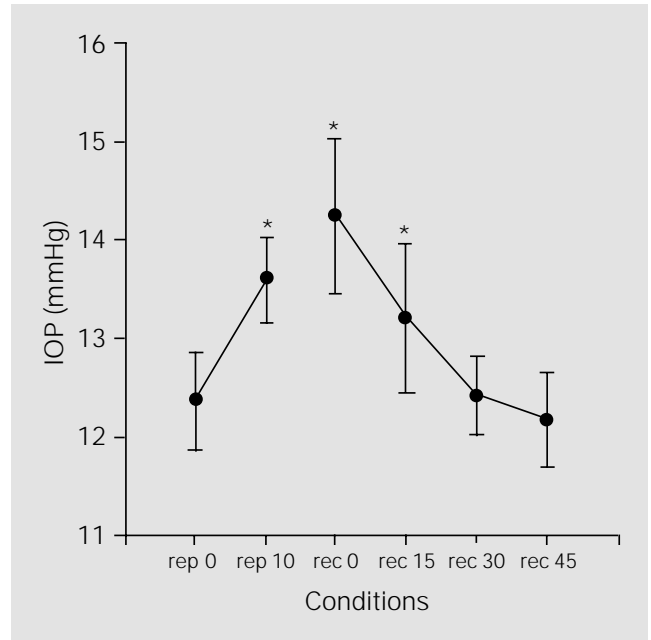

Figure 1. Pre- and post-exercise intraocular pressure (IOP) and water intake for both the right and left eye. Data are reported as means \pm SD of $\mathrm{mmHg}$. rep $0=$ first measurement of IOP at rest; rep $10=$ IOP $10 \mathrm{~min}$ after $600 \mathrm{ml}$ of water ingestion; rec 0 to rec $45=$ IOP at 15-min intervals after the end of exercise on a bicycle or after the equivalent period of rest. Least significant difference between data $=1.20 ; * \mathrm{P}<0.05$ compared to rep 0 (Tukey test).

Table 1. Physiological variables.

\begin{tabular}{|c|c|c|c|c|c|c|c|c|c|}
\hline $\mathrm{H}_{2} \mathrm{O}$ & Condition & $\mathrm{ET}_{\max }$ & $\Delta \mathrm{T}_{\text {rec }}$ & $\% \mathrm{H}$ & $H R$ & $\mathrm{VO}_{2}$ & $\mathrm{VCO}_{2}$ & $\mathrm{La}_{\mathrm{a}}$ & $T_{\text {env }}$ \\
\hline $10^{\circ} \mathrm{C}$ & Resting & - & $-0.7 \pm 0.3$ & $0.9 \pm 0.5$ & $60.3 \pm 10.4$ & $0.26 \pm 0.07$ & $0.25 \pm 0.03$ & $1.02 \pm 0.09$ & $22.8 \pm 0.75$ \\
\hline $24^{\circ} \mathrm{C}$ & Resting & - & $-0.5 \pm 0.4$ & $1.0 \pm 0.9$ & $63.0 \pm 6.5$ & $0.23 \pm 0.04$ & $0.20 \pm 0.05$ & $0.96 \pm 0.13$ & $22.8 \pm 0.26$ \\
\hline $38^{\circ} \mathrm{C}$ & Resting & - & $-0.3 \pm 0.4$ & $0.7 \pm 0.6$ & $59.8 \pm 11.6$ & $0.21 \pm 0.05$ & $0.19 \pm 0.03$ & $0.76 \pm 0.20$ & $22.5 \pm 0.55$ \\
\hline $10^{\circ} \mathrm{C}$ & Exercise & $91.5 \pm 23.7$ & $0.6 \pm 0.3$ & $-0.7 \pm 0.6$ & $155.8 \pm 5.9$ & $2.01 \pm 0.23$ & $1.93 \pm 0.29$ & $1.89 \pm 1.50$ & $22.5 \pm 0.97$ \\
\hline $24^{\circ} \mathrm{C}$ & Exercise & $93.9 \pm 24.5$ & $0.8 \pm 0.2$ & $-0.6 \pm 0.9$ & $157.8 \pm 8.7$ & $1.97 \pm 0.17$ & $2.06 \pm 0.32$ & $1.73 \pm 0.32$ & $22.5 \pm 0.49$ \\
\hline $38^{\circ} \mathrm{C}$ & Exercise & $93.8 \pm 27.0$ & $0.7 \pm 0.3$ & $-0.5 \pm 0.6$ & $149.8 \pm 8.1$ & $2.04 \pm 0.34$ & $1.88 \pm 0.27$ & $1.47 \pm 0.25$ & $22.4 \pm 0.49$ \\
\hline \multirow{2}{*}{\multicolumn{2}{|c|}{ Rest $x$ exercise }} & - & $*$ & * & $*$ & $*$ & $*$ & $*$ & NS \\
\hline & & NS & NS & NS & NS & NS & NS & NS & NS \\
\hline
\end{tabular}

Data are reported as means $\pm \mathrm{SEM}$ for 6 subjects. $\mathrm{H}_{2} \mathrm{O}$ temp = temperature of ingested water; $\mathrm{ET}_{\text {max }}=$ maximal exercise time $(\mathrm{min}) ; \Delta \mathrm{T}_{\text {rec }}=$ difference between final and initial rectal temperature $\left({ }^{\circ} \mathrm{C}\right) ; \% \mathrm{H}=$ final hydration status (\% of corporal weight); $\mathrm{HR}=$ final heart rate $(\mathrm{min}) ; \mathrm{VO}_{2}=$ final oxygen consumption ( $(/ \mathrm{min}) ; \mathrm{VCO}_{2}=$ final carbonic gas extraction $(\mathrm{l} / \mathrm{min}) ; \mathrm{L}_{\mathrm{a}}=$ final plasma lactate $(\mathrm{mmol} / \mathrm{l}) ; \mathrm{T}_{\text {env }}=$ environmental temperature $\left({ }^{\circ} \mathrm{C}\right)$.

$* \mathrm{P}<0.05$ comparing rest with exercise (Tukey test). NS $=\mathrm{P}>0.05$. 
tically significant increase in IOP was observed between the first and the second, the first and the third, and the first and the fourth measurements of IOP, in both exercising and resting sessions. There were no significant differences in IOP between the resting and exercising conditions (Figure 1).

Time to exhaustion was not affected by the different water temperatures. Rectal temperature, hydration status, heart rate, oxygen consumption, carbonic gas extraction, and lactate concentration were increased by exercise but were not affected by the different water temperatures. The subjects had an average loss of $0.3 \mathrm{~kg}$ body weight during exercise and an average increase of $0.5 \mathrm{~kg}$ during the resting period. All experiments were performed under similar environmental conditions (Table 1).

The present study addressed some of the possible variables related to IOP responses to physical exercise, i.e., heart rate, blood lactate, blood gases, hydration status, environmental conditions and body temperature, and their relations to the temperature of the ingested water.

Most papers reviewed report a decrease in IOP after different types of exercises (29,12-18). Some studies showed increases of IOP after exercise $(1,19)$, while others found either no effect on IOP or variable results (20).

The lack of standardization in the experimental procedures appears to be the main reason for the lack of agreement in the literature concerning the effects of exercise on IOP. Factors like food or water ingestion and postural variations were not well controlled previously or even considered. These methodological errors and dissimilarities between published data make it difficult to reach definitive conclusions about the effect of exercise on IOP.

Certain inverse relationships have been found between osmolarity and IOP (5.8) and these changes in IOP have been attributed to serum lactate or blood $\mathrm{pH}$ by some authors
$(5,6,8)$.

The loss of water and electrolytes that occurs during exercise may affect plasma osmolarity and volume, which could cause changes in IOP. In the present study, heart rate, blood lactate, mean skin temperature, oxygen consumption, carbonic gas extraction, and hydration status were consistently different between rest and exercise, but no significant differences in IOP were found between exercising and resting conditions. Furthermore, the temperature of the water ingested by the volunteers during the different experimental treatments did not influence the IOP results.

The variations in IOP - an initial increase followed by a return to basal values (Figure 1) - were similar during exercise and rest and were probably due to the ingestion of water, a result previously reported in the literature (11).

The volunteers had an average loss of 0.3 $\mathrm{kg}$ body weight during exercise, caused by ingestion of $1320 \mathrm{ml}$ of water. During the resting period there was an average increase of $0.5 \mathrm{~kg}$ in body weight. On the other hand, IOP showed the same pattern and magnitude of variation in both situations, i.e., exercise and rest. This fact suggests that the effect of drinking water on IOP was dependent on the initial ingestion of water, as reported previously. The return of IOP toward basal values occurred both after exercise and rest regardless of the relative level of hydration, as shown by the differences in mean body weight. It seems, therefore, that the rapid intake of water caused the variations observed in IOP and that exercise or rest did not influence IOP. The temperature of the water also had no influence on these results.

In the present study, a difference in rectal temperature was observed between rest and exercise. The behavior of IOP was the same in both situations, indicating that the variations in body temperature within these physiological limits did not influence IOP.

We may conclude that metabolic changes 
induced by exercise under conditions of water ingestion or the temperature of the ingested water had no significant effects on IOP. In fact, only a transient increase in IOP was observed, related to the ingestion of water.

\section{References}

1. American College of Sports Medicine (1987). Position stand - The prevention of thermal injuries during distance running. Medicine and Science in Sports and Exercise, 19: 529-533.

2. Lempert $\mathrm{P}$, Cooper $\mathrm{KH}$, Culver JF \& Tredict TJ (1967). The effect of exercise on intraocular pressure. American J ournal of Ophthalmology, 63: 1673-1676.

3. Leighton DA \& Phillips Cl (1970). Effect of moderate exercise on the ocular tension. British J ournal of Ophthalmology, 54: 599605.

4. Marcus DF, Krupin T, Podos SM \& Becker $B$ (1970). The effect of exercise on intraocular pressure. I. Human beings. Investigative Ophthalmology and Visual Science, 9: 749-752.

5. Marcus DF, Edelhauser HF, Maksud MG \& Wiley RL (1974). Effects of a sustained muscular contraction on human intraocular pressure. Clinical Science and M olecular Medicine, 47: 249-257.

6. Qureshi IA (1995). Effects of mild, moderate and severe exercise on intraocular pressure of sedentary subjects. Annals of Human Biology, 22: 545-553.

7. Stewart RH, Leblanc R \& Becker B (1970). Effects of exercise on aqueous dynamics. American J ournal of Ophthalmology, 69: 245-248.

8. Martin B, Harris A, Hammel $T \&$ Mali- novsky V (1999). Mechanism of exerciseinduced ocular hypotension. Investigative Ophthalmology and Visual Science, 40: 1011-1015.

9. Krupin T, Bass J , Oestrich C, Podos SM \& Becker B (1977). The effect of hyperthermia on aqueous humor dynamics in rabbits. American J ournal of Ophthalmology, 83: 561-564.

10. Whitacre MM \& Stein R (1993). Sources of error with use of Goldmann-type tonometers. Survey of Ophthalmology, 38: 1-30.

11. Drance SM (1963). Studies with applanation water tests. Archives of Ophthalmology, 69: 39-43.

12. Shapiro A, Shoenfeld $Y \&$ Shapiro $Y$ (1978). The effect of standardized submaximal workload on intraocular pressure. British J oumal of Ophthalmology, 62: 679-681.

13. Passo MS, Goldberg L \& Elliot DL (1987). Exercise conditioning and intraocular pressure. American J ournal of Ophthalmology, 103: 754-757.

14. Passo MS, Goldberg L, Elliot DL \& Buskirk EM (1991). Exercise training reduces intra-ocular pressure among subjects suspected of having glaucoma. Archives of Ophthalmology, 109: 1096-1098.

15. Harris A, Malinovsky VE, Cantor LB, Henderson PA \& Martin BJ (1992). Isocapnia blocks exercise-induced reductions in ocular tension. Investigative Ophthalmology and Visual Science, 33: 2229-2232.

16. Kiuchi $Y$, Mishima HK, Hotehama $Y$, Furumoto A, Hirota A \& Onari K (1994). Exercise intensity determines the magnitude of IOP decrease after running. J apanese J ournal of Ophthalmology, 38: 191195.

17. Orgul S \& Flammer J (1994). Moderate exertion lasting only seconds reduces intraocular pressure. Graefe's Archive for Clinical and Experimental Ophthalmology, 232: 262-264.

18. Qureshi IA (1996). Effects of exercise on intraocular pressure in physically fit subjects. Clinical and Experimental Pharmacology and Physiology, 23: 648-652.

19. Dickerman RD, Smith $G H$, Langham-Roof L, McConathy WJ , East J W \& Smith AB (1999). Intra-ocular pressure changes during maximal isometric contraction: does this reflect intra-cranial pressure or retinal venous pressure? Neurological Research, 21: 243-246.

20. Era P, Parssinen O \& Kallinen M (1993). Effect of bicycle ergometer test on intraocular pressure in elderly athletes and controls. Acta Ophthalmologica Scandinavica, 71: 301-307. 